\begin{tabular}{llrr}
\hline \hline Volume: & 3 & E-ISSN: & $2655-1942$ \\
Number: & 1 & Terbitan: & April 2020 \\
Page : & $15-28$ & & \\
\hline
\end{tabular}

\title{
Peran Pemerintah dalam Pengelolaan Limbah Medis pada Apotek dan Praktik Bidan Mandiri
}

\author{
Adhi Putra Satria \\ Fakultas Hukum Universitas 17 Agustus 1945 Semarang \\ Email: putraadhisatria1@gmail.com
}

\begin{abstract}
Absrak
Penelitian ini akan menganalisis bagaimana peran pemerintah dalam pengelolaan limbah medis pada Apotik dan praktik bidan mandiri, serta bagaimana hambatannya. Penelitian ini didasarkan pada data sekunder, yaitu Undang-Undang, kemudian oleh penulis dianalisis, hingga menemukan suatu permasalahan dalam pengelolaan limbah medis di Indonesia saat ini. Hasil penelitian menunjukan, saat ini pemerintah sudah menggunakan kewenangannya dalam mengelola limbah medis yang dihasilkan oleh aktifitas pelayanan kesehatan, dimana kewenangannya tersebut diatur dalam peraturan menteri lingkungan hidup dan kehutanan nomor P.56/melhk-setjen/2015, namun ruang lingkup pengaturan dalam peraturan tersebut, hanya ditunjukkan bagi pengelolaan limbah yang dihasilkan oleh rumah sakit, klinik, dan puskesmas saja. Hal tersebut mengakibatkan ketidakpastian hukum terhadap pengelolaan limbah medis pada pelayanan kesehatan seperti, Apotik, dan praktik bidan mandiri. Sehingga kesimpulan penelitian ini, adalah memberikan masukan agar pemerintah merevisi kembali pengaturan mengenai pengelolaan limbah medis dengan cara memperluas ruang lingkup pengaturan limbah medis untuk seluruh fasilitas pelayanan kesehatan termasuk Apotik, dan praktik bidan mandiri.
\end{abstract}

Kata kunci: Limbah; Rumah Sakit; Pelayanan Kesehatan.

\section{Abstract}

This study will analyze how the government plays a role in the management of medical waste in pharmacies and independent midwife practices, as well as the obstacles. This research is based on secondary data, namely the Law, then analyzed by the author, to find a problem in the management of medical waste in Indonesia today. The results of the study show that currently the government has used its authority in managing medical waste generated by health service activities, where the authority is regulated in Minister of Environment and Forestry Regulation number P.56 / melhk-setjen /2015, but the scope of the regulation is in the regulation, it is only intended for the management of waste generated by hospitals, clinics, and health centers. This results in le gal uncertainty about the management of medical waste in health services such as pharmacies and independent midwife practices. So the conclusion of this study, is to provide input for the government to revise the regulations regarding the management of medical waste by expanding the scope of medical waste management for all health service facilities including pharmacies, and the practice of independent midwives.

Keywords: Waste; Hospital; Health services. 


\begin{tabular}{llrr}
\hline \hline Volume: & 3 & E-ISSN: & $2655-1942$ \\
Number: & 1 & Terbitan: & April 2020 \\
Page : & $15-28$ & & \\
\hline
\end{tabular}

\section{A. Latar Belakang Masalah}

Konstitusi negara Indonesia setelah diamandemen telah mengakomodir berbagai hak asasi manusia yang diatur di dalamnya, salah satunya adalah hak asasi manusia dibidang lingkungan hidup, ${ }^{1}$ negara Indonesia telah berkomitmen penuh terhadap hak asasi manusia tersebut dengan berupaya untuk terus melindungi, memenuhi dan menghormati hak masyarakat Indonesia guna mencapai kesejahteraan, dengan cara memperoleh jaminan atas kesehatan fisik maupun kesehatan lingkungan. ${ }^{2}$

Pemerintah Indonesia telah melakukan berbagai upaya yang dilakukan dalam rangka menjamin hak asasi manusia dibidang lingkungan hidup, salah satunya adalah dengan cara melakukan upaya kesehatan lingkungan. Kesehatan lingkungan, merupakan serangkaian cara dan upaya preventif untuk meningkatkan kualitas kesehatan lingkungan. ${ }^{3}$ Upaya-upaya tersebut dilakukan oleh pemerintah dalam rangka mewujudkan hak masyarakat untuk mendapatkan akses atas kualitas lingkungan yang sehat, baik kesehatan lingkungan secara fisik, kimia, biologi, hingga social, sehingga hal demikian memungkinkan setiap masyarakat Indonesia dapat mencapai derajat kesehatan yang setinggi-tingginya. ${ }^{4}$

Permasalahan lingkungan hidup pada saat ini masih terus menjadi wacana publik, kerusakan lingkungan menjadi ancaman terbesar yang dapat mengakibatkan hilangnya akses masyarakat Indonesia atas jaminan tersedianya kualitas lingkungan hidup yang baik. Dalam bahasa yang sederhana bahwa pelanggaran atas kerusakan lingkungan hidup, merupakan pelanggaran pula

\footnotetext{
${ }^{1}$ Nopyandri, Hak atas Lingkungan Hidup dan Kaitannya dengan Peran Serta dalam Pengelolaan Lingkungan Hidup dalam Perspektif Otonomi Daerah, Jurnal Inovatif, Volume VII Nomor III September 2014, halaman 33

${ }^{2}$ Bunga Agustina, Kewenangan Pemerintah dalam Perlindungan Hukum Pelayanan Kesehatan Tradisional Ditinjau Dari Undang-Undang Republik Indonesia No 36 Tahun 2009 Tentang Kesehatan, Jurnal Wawasan Hukum, Vol. 32, No. 1, Februari 2015, Halaman 84.

${ }^{3}$ Mugeni Sugiharto, Oktarina, Environmental Health Program Implementation at Public Health Center (PHC) in Tuban District) - East Java Proviace (Analysis Data of National Health Facilities Research 2011), Buletin Penelitian Sistem Kesehatan - Vol. 17 No. 1 Januari 2014: halaman 17

${ }^{4}$ Rosmidah Hasibuan, Pengaturan Hak Atas Lingkungan Hidup Terhadap Kesehatan, Jurnal Ilmiah “Advokasi” Vol. 06. No. 02 September 2018, halaman 93
} 


\begin{tabular}{llrr}
\hline \hline Volume: & 3 & E-ISSN: & 2655-1942 \\
Number: & 1 & Terbitan: & April 2020 \\
Page : & $15-28$ & & \\
\hline
\end{tabular}

terhadap HAM. ${ }^{5}$ Pada saat ini ancaman kerusakan lingkungan hidup yang dapat mengakibatkan tidak terpenuhinya hak masyarakat untuk mendapatkan jaminan atas lingkungan hidup yang layak disebabkan oleh berbagai faktor yang melatarbelakangi nya. Dari sekian banyak faktor yang dapat mencemari kualitas lingkungan hidup salah satunya adalah limbah medis yang dihasilkan oleh adanya aktifitas pelayanan di rumah sakit dan fasilitas kesehatan lainya. ${ }^{6}$

Berdasarkan Pasal 1 angka (7) Undang-Undang No 36 tahun 2009 Tentang Kesehatan menyebutkan bahwa yang dimaksud dengan Fasilitas pelayanan kesehatan adalah "Suatu alat dan/atau tempat yang digunakan untuk menyelenggarakan upaya pelayanan kesehatan, baik promotif, preventif, kuratif maupun rehabilitatif yang dilakukan oleh Pemerintah, pemerintah daerah, dan/atau masyarakat ${ }^{7}$."

Dalam melaksanakan fungsi dan tugasnya fasilitas kesehatan dapat memproduksi dan menghasilkan limbah yang berpotensi mencemari lingkungan dan pada akhirnya dapat menurunkan kualitas terhadap lingkungan hidup, selain itu fasilitas kesehatan juga dapat menyebabkan berbagai macam kecelakaan hingga menimbulkan penularan penyakit apabila dalam pengelolaan limbah medis tersebut belum atau tidak sesuai dengan peraturan yang sudah ditetapkan oleh pemerintah. ${ }^{8}$ Atas dasar hal demikian maka dapat disimpulkan bahwa fasilitas kesehatan yang tidak mengelola limbah medis yang dihasilkan nya secara baik dapat memberikan dampak negatif dari aspek kesehatan lingkungan serta menjadi sumber masalah bagi lingkungan dan kesehatan. ${ }^{9}$

\footnotetext{
${ }^{5}$ Rochmani, Perlindungan Hak Atas Lingkungan Hidup Yang baik Dan Sehat Di Masa Globalisasi, Jurnal Masalah-Masalah Hukum Vol 44 No 1 Januari 2015, halaman 1

${ }^{6}$ Hanna Niken J Sihotang et al., Pertanggungjawaban Rumah Sakit Terkait dengan Tindak Pidana Lingkungan Hidup Yang Dilakukan Pegawai Rumah Sakit, USU Law Journal, Vol.3.No.1(April 2015) Halaman 203

${ }^{7}$ Achmad Busro, 'Aspek Hukum Persetujuan Tindakan Medis (Inform Consent) Dalam Pelayanan Kesehatan', Law \& Justice Journal, 2018 <https://doi.org/10.14710/ldjr.v1i1.3570>. halaman 2.

8 Aymen Abd-ULSalam Awad, Enviromental Impact of Medical Waste Treatment And Management By Buring Inside Health Facilities, International Journal of Civil Engineering and Technology, Volume 9, Issue 5, May 2018, pp. 41-53

${ }^{9}$ Kementerian Lingkungan Hidup dan Kehutanan, 2018, Peta Jalan (Roadmap)Pengelolaan Limbah B3 dari Fasilitas Pelayanan Kesehatan (Fasyankes) Direktorat Penilaian Kinerja Pengelolaan Limbah B3 dan Limbah Non B3 : Jakarta halaman1.1
} 


\begin{tabular}{llrr}
\hline \hline Volume: & 3 & E-ISSN: & $2655-1942$ \\
Number: & 1 & Terbitan: & April 2020 \\
Page : & $15-28$ & & \\
\hline
\end{tabular}

Limbah yang dihasilkan oleh fasilitas kesehatan dan dapat memberikan ancaman terhadap kualitas kesehatan manusia serta lingkungan yaitu limbah yang dapat menyebabkan penyakit menular (Infectious Waste), limbah tersebut antara lain seperti limbah human anatomical, limbah tubuh hewan, limbah laboratorium, limbah darah atau limbah cairan manusia dan peralatan yang terkontaminasi baik langsung atau tidak langsung dengannya serta limbah-limbah benda tajam seperti contoh jarum suntik, gunting pecahan kaca dan lain-lain.

Pada saat ini pengaturan mengenai penanganan pengelolaan limbah medis yang dihasilkan oleh pelayanan kesehatan telah diatur dalam peraturan menteri lingkungan hidup dan kehutanan nomor P.56/melhk-setjen/2015 tentang tata cara dan persyaratan teknis pengelolaan limbah bahan berbahaya beracun dari fasilitas pelayanan kesehatan. ${ }^{10}$ Namun, peraturan tersebut hanya mengatur mengenai penanganan pengelolaan limbah medis yang dihasilkan oleh Rumah Sakit klinik, dan Puskesmas saja, peraturan tersebut tidak mengatur mengenai teknis pelaksanaan penanganan limbah medis yang dihasilkan oleh aktifitas pelayanan kesehatan lain, seperti apotek, dokter dan praktik bidan mandiri.

Tidak diaturnya tentang teknis penanganan pengelolaan limbah medis menyebabkan ancaman yang serius bagi kualitas lingkungan hidup yang sehat, mengingat limbah medis, karena sifat atau bentuk nya yang dapat dikategorikan sebagai limbah yang berbahaya, tidak hanya dihasilkan oleh pelayanan kesehatan pada rumah sakit, klinik dan puskesmas saja, melainkan pelayanan kesehatan lainya juga berpotensi menghasilkan limbah medis yang berbahaya, yang apabila penanganan nya tidak maksimal akan berakibat pada ancaman penurunan kualitas lingkungan hidup di Indonesia.

Limbah yang dihasilkan oleh aktifitas pelayanan kesehatan yang dilakukan oleh Apotik, dan praktik bidan mandiri, merupakan limbah B3 yang apabila ditangani dengan tidak serius akan mengancam baik terhadap penurunan kualitas lingkungan hidup, hingga penurunan terhadap kesehatan masyarakat, seperti

\footnotetext{
${ }^{10}$ Mirawati et al. Analisis Sistim Pengelolaan Limbah Medis Padat Di Puskesmas Pangi Parigi Kabupaten Parigi Moutong, Jurnal Kolaboratif Sains Vol 1 No 1 tahun 2019,halaman 1-2
} 


\begin{tabular}{llrr}
\hline \hline Volume: & 3 & E-ISSN: & $2655-1942$ \\
Number: & 1 & Terbitan: & April 2020 \\
Page : & $15-28$ & & \\
\hline
\end{tabular}

contoh, praktik bidan mandiri, ${ }^{11}$ akan menghasilkan limbah darah dalam aktifitas pelayanan kesehatan yang dilakukannya, limbah darah, apabila penanganannya tidak tepat, berpotensi akan menularkan penyakit terhadap manusia, terutama apabila darah tersebut terbukti telah terinfeksi penyakit HIV.

Peran pemerintah sangat penting dalam menjamin tentang bagaimana perlindungan hukum masyarakat dan lingkungan terhadap ancaman limbah medis yang bersumber dari adanya aktifitas pelayanan kesehatan pada Apotik, dan praktik bidan mandiri. Atas dasar latar belakang sebagaimana telah dijabarkan diatas, maka penulis tertarik untuk meneliti dan mengkaji permasalahan tersebut diatas, dengan pembahasan yang akan difokuskan pada pertanyaan penelitian yaitu bagaimana kewenangan pemerintah dalam pengelolaan limbah medis pada Apotik, dan praktik bidan mandiri, serta bagaimana hambatan yang terjadi.

\section{B. Metode Penelitian}

Soerjono Soekanto dalam bukunya "pengantar penelitian hukum" mendefinisikan metode sebagai sebuah proses prinsip-prinsip, dan tata cara dalam memecahkan suatu masalah, sedangkan penelitian didefinisikan sebagai sebuah proses pemeriksaan yang dilakukan secara cermat dan hati-hati, terhadap suatu gejala yang bertujuan dalam rangka untuk menambah pengetahuan manusia. ${ }^{12}$ Berdarakan pada definisi tentang metode dan penelitian sebagaimana dijelaskan diatas, maka dapat disimpulkan bahwa Metode penelitian adalah suatu rangkaian cara atau proses kegiatan pelaksanaan penelitian yang berdasr pada berbagai asumsi-asumsi dasar, pandangan-pandangan filosofis ideologis, dan pertanyaan serta isu yang sedang dihadapi. Suatu penelitian harus memiliki sebuah rancangan penelitian (research design) tertentu. Dimana rancangan itu menggambarkan prosedur atau langkah-langkah yang wajib ditempuh, seperti waktu penelitian,

\footnotetext{
${ }^{11}$ Robert Ohene Adu et al. Medical Waste-Sorting and Management Practices in Five Hospitals in Ghana, Journal of Environmental and Public Health Volume 4 March 2020, Page 2

${ }^{12}$ Soerjono Soekanto, Pengantar Penelitian Hukum, (Jakarta:UI Perss, 2007) halaman 6
} 


\begin{tabular}{llrr}
\hline \hline Volume: & 3 & E-ISSN: & 2655-1942 \\
Number: & 1 & Terbitan: & April 2020 \\
Page : & $15-28$ & & \\
\hline
\end{tabular}

sumber data dan kondisi data serta cara bagaimana data tersebut dihimpun dan diolah. $^{13}$

Pendekatan masalah dalam penulisan artikel ini adalah pendekatan yuridis normatif. Pendekatan yuridis normatif merupakan sebuah pendekatan yang dalam pelaksanaanya didasarkan kepada berbagai peraturan perundang-undangan, ${ }^{14}$ teori-teori, dan konsep-konsep yang berkorelasi dengan penelitian ini. Spesifikasi penelitian dilakukan oleh penulis dengan berdasarkan pada perumusan masalah yang akan dijelaskan dengan cara deskriptif analisis. Adapun deskriptif analitis dalam penelitian ini akan berusaha memberikan gambaran kepada pembaca secara menyeluruh, tersistematis dan mendalam prihal adanya suatu keadaan atau gejala yang sedang diteliti. ${ }^{15}$

Dalam penelitian ini penulis akan menguraikan dan menggambarkan secara menyeluruh terkait dengan hambatan-hambatan pelaksanaan pengelolaan limbah medis di Indonesia, dalam penelitian ini juga penulis akan mencoba menjelaskan dan menggambarkan mengenai solusi apa yang perlu dilakukan atas permasalahan tersebut.

Sumber data dalam penelitian ini adalah data berupa studi kepustakaan, dimana data tersebut diperoleh dari peraturan perundang-undangan terkait, dan laporan-laporan yang berkaitan dengan penelitian ini. Jenis data yang digunakan dalam penelitian ini merupakan data yang penulis dapat dari berbagai bahan hukum yang terdiri dari:

a. Bahan hukum primer meliputi antara lain seluruh peraturan perundangundangan.

b. Bahan hukum sekunder yaitu bahan hukum yang membantu pemahaman penulis dalam menganalisa serta memahami permasalahan yang sedang diteliti dalam bentuk, buku, arsip dan dokumen, jurnal, brosur dan lain-lain

c. Terakhir adalah bahan hukum tersier yaitu bahan hukum terdiri dari kamus bahasa indonesia dan kamus hukum.

\footnotetext{
${ }^{13}$ Zainudi Ali, Metode Penelitian Hukum, (Jakarta:Sinar Grafika,2009), halaman 17

${ }^{14}$ Kornelius Benuf and Muhamad Azhar, 'Metodologi Penelitian Hukum Sebagai Instrumen Mengurai Permasalahan Hukum Kontemporer', Gema Keadilan, 7.1 (2020), 20-33.

${ }^{15}$ Soerjono Soekanto, Pengantar Penelitian Hukum, (UI Press, Jakarta 1984), halaman 10
} 


\begin{tabular}{llrr} 
Volume: & 3 & E-ISSN: & 2655-1942 \\
Number: & 1 & Terbitan: & April 2020 \\
Page : & $15-28$ & & \\
\hline
\end{tabular}

\section{Hasil Penelitian dan Pembahasan}

1. Kewenangan pemerintah dalam pengelolaan limbah medis Apotik, dan praktik bidan mandiri

Pemerintah memiliki kewenangan dalam hal mengelola limbah medis yang bersumber dari fasilitas kesehatan Apotik, dan praktik bidan mandiri, kewenangan tersebut tidak terlepas bahwa pemerintah memiliki kewenangan dalam menetapkan berbagai kebijakan-kebijakan sebagai landasan hukum dalam menjalankan aktifitas kenegaraanya ${ }^{16}$ dimana dalam hal penulisan ini kebijakan sebagaimana dimaksud adalah kebijakan yang mengatur mengenai teknik pengelolaan limbah medis yang baik, pada semua fasilitas kesehatan yang diakui keberadaannya berdasarkan peraturan yang berlaku.

Sebelum masuk ke dalam pembahasan penulis ingin menjelaskan, bahwa fasilitas kesehatan seperti Apotik, dan praktik bidan mandiri, merupakan fasilitas kesehatan yang dalam menjalankan aktivitasnya dapat menghasilkan limbah medis, yang mana limbah medis tersebut termasuk pada limbah yang bersifat infeksius dan dapat dikategorikan sebagai limbah B3. ${ }^{17}$ Konsekuensi apabila suatu limbah yang sudah dikategorikan sebagai limbah B3, maka penanganan pengelolaannya perlu dilakukan secara khusus. Pengelolaan limbah medis yang termasuk dalam kategori limbah B3, kewenangan pengelolaannya diserahkan kepada pemerintah pusat, Hal tersebut diatur di dalam pasal 23 ayat (1) UndangUndang No 18 Tahun 2008 Tentang Pengelolaan Sampah, yang dengan tegas menyebutkan bahwa, "pengelolaan sampah spesifik (sampah yang berkategori limbah B3) pengelolaannya menjadi tanggung jawab pemerintah pusat”.

Pemerintah Republik Indonesia, telah mengeluarkan berbagai kebijakan tentang pengelolaan limbah yang termasuk ke dalam kategori limbah B3, seperti limbah medis. Kebijakan mengenai teknis penanganan limbah B3, diatur didalam Peraturan Pemerintah No 101 Tahun 2014 Tentang Pengelolaan limbah B3. Dalam Peraturan tersebut sudah dijelaskan bahwa teknis penanganan pengelolaan

\footnotetext{
${ }^{16}$ Firman Freaddy Busroh, Konseptualisasi Omnibuslaw dalam Menyelesaikan Regulasi Pertanahan, ARENA HUKUM Volume 10, Nomor 2, Agustus 2017, Halaman 227-250

17 Dewi Mustika, Analisis Pengelolaan Sampah Medis Pelayanan Kesehatan Praktik Bidan Swasta di Kota Banjar Baru, Jurnal Enviro Scienteae Volume 10 No 3 November 2014 118-123
} 


\begin{tabular}{llrr}
\hline \hline Volume: & 3 & E-ISSN: & $2655-1942$ \\
Number: & 1 & Terbitan: & April 2020 \\
Page : & $15-28$ & & \\
\hline
\end{tabular}

limbah B3 dilakukan dengan cara meliputi, "penetapan limbah B3, pengurangan limbah B3, penyimpanan limbah B3, pengumpulan limbah B3, pengangkutan limbah B3, pemanfaatan limbah B3, pengolahan limbah B3, dan pembuangan limbah B3".

Teknis penanganan pengelolaan limbah B3 sebagaimana disebutkan diatas, perlu dilakukan mengingat dampak dari limbah B3 yang di dalamnya termasuk limbah medis yang dihasilkan oleh adanya aktifitas pelayanan kesehatan pada Apotik, dan praktik bidan mandiri, akan mempengaruhi terhadap kualitas kesehatan di lingkungan tempat aktifitas pelayanan kesehatan itu dilakukan. Hal ini sesuai dengan apa yang dikatakan dalam pasal 163 ayat (1) dan (2) UndangUndang no 36 tahun 2009 tentang kesehatan, yang menyebutkan bahwa "pemerintah perlu menjamin tersedianya lingkungan yang sehat dan tidak mempunyai resiko yang buruk bagi kesehatan di lingkungan pemukiman, tempat kerja, tempat rekreasi serta tempat dan fasilitas umum".

Kewenangan pemerintah dalam mengelola limbah medis yang dihasilkan dan bersumber dari adanya aktifitas pelayanan kesehatan di Apotik, klinik dan praktik bidan mandiri, perlu dilakukan oleh pemerintah dengan cara mengelola limbah medis yang berwawasan lingkungan, dengan tugas utama pemerintah dalam mengelola limbah tersebut yaitu dengan cara yang sesuai dengan UndangUndang No 18 Tahun 2008 Tentang Pengelolaan Sampah yang mengamanatkan agar pemerintah dapat: ${ }^{18}$

a. "Menumbuhkembangkan dan meningkatkan kesadaran masyarakat dalam pengelolaan sampah";

b. "Melakukan penelitian, pengembangan teknologi pengurangan, dan penanganan sampah";

c. "Memfasilitasi, mengembangkan, dan melaksanakan upaya pengurangan, penanganan, dan pemanfaatan sampah";

\footnotetext{
${ }^{18}$ Sri Nurhayati Qodriyatun, Bentuk Lembaga Yang Ideal Dalam Pengelolaan Sampah Di Daerah (Sudi di Kota Malang dan Kabupaten Gianyar), Jurnal Aspirasi Vol. 6 No. 1, Juni 2015 halaman $1-12$.
} 


\begin{tabular}{llrr}
\hline \hline Volume: & 3 & E-ISSN: & $2655-1942$ \\
Number: & 1 & Terbitan: & April 2020 \\
Page : & $15-28$ & & \\
\hline
\end{tabular}

d. "Melaksanakan pengelolaan sampah dan memfasilitasi penyediaan prasarana dan sarana pengelolaan sampah";

e. "Mendorong dan memfasilitasi pengembangan manfaat hasil pengolahan sampah";

f. "Memfasilitasi penerapan teknologi spesifik lokal yang berkembang pada masyarakat setempat untuk mengurangi dan menangani sampah"; dan

g. "Melakukan koordinasi antar lembaga pemerintah, masyarakat, dan dunia usaha agar terdapat keterpaduan dalam pengelolaan sampah".

2. Hambatan dalam pengelolaan limbah medis Apotik, dan praktik bidan mandiri

Pengelolaan limbah medis pada fasilitas pelayanan kesehatan yang dilakukan oleh Apotik, dan praktik mandiri bidan tidak selalu berjalan mulus, dalam perjalanannya pengelolaan limbah pada pelayanan kesehatan, yang kewenangannya dilaksanakan oleh pemerintah mendapat berbagai hambatanhambatan, hambatan sebagaimana dimaksud adalah hambatan tentang ketidakjelasan pengaturan pengelolaan limbah di pelayanan kesehatan saat ini.

Pengelolaan limbah medis pada pelayanan kesehatan diatur secara spesifik dalam peraturan menteri lingkungan hidup dan kehutanan nomor P.56/melhksetjen/2015 tentang tata cara dan persyaratan teknis pengelolaan limbah bahan berbahaya beracun dari fasilitas pelayanan kesehatan. Dalam peraturan ini secara jelas sudah diatur mengenai teknik pengelolaan limbah B3 yang dihasilkan oleh aktifitas pelayanan kesehatan. Namun, yang menjadi permasalahan adalah, pada saat peraturan menteri lingkungan hidup dan kehutanan nomor P.56/melhksetjen/2015 membatasi ruang lingkup pengaturan mengenai teknik pengelolaan limbah medis tersebut hanya pada fasilitas kesehatan yang meliputi: "Pusat kesehatan masyarakat, Klinik pelayanan kesehatan atau sejenis, dan Rumah sakit".

Pemberlakuan pengelolaan limbah medis itu juga ditunjukkan bagi fasilitas pelayanan kesehatan yang sudah terdaftar dalam instansi yang bertanggungjawab dibidang kesehatan, sehingga terhadap fasilitas kesehatan yang belum terdaftar 


\begin{tabular}{llrr}
\hline \hline Volume: & 3 & E-ISSN: & 2655-1942 \\
Number: & 1 & Terbitan: & April 2020 \\
Page : & $15-28$ & & \\
\hline
\end{tabular}

dalam instansi pemerintah yang bertanggung jawab dibidang kesehatan, tidak menjadi ruang lingkup pengaturan di dalam peraturan ini.

Peraturan menteri lingkungan hidup dan kehutanan nomor P.56/melhksetjen/2015 tentang tata cara dan persyaratan teknis pengelolaan limbah bahan berbahaya beracun dari fasilitas pelayanan kesehatan, apabila dianalisis bertolak belakang dengan Peraturan Pemerintah No 47 Tahun 2016 tentang fasilitas pelayanan kesehatan, yang mana dalam Peraturan Pemerintah tersebut telah mengatur dan menegaskan bahwa ruang lingkup fasilitas pelayanan kesehatan mencakup antara lain yaitu antara lain seperti "Tempat praktik mandiri tenaga kesehatan, Pusat kesehatan masyarakat, Klinik, Rumah sakit, Apotek, Unit transfusi darah, Laboratorium kesehatan, Optikal, Fasilitas pelayanan kedokteran untuk kepentingan hukum, dan Fasilitas pelayanan kesehatan tradisonal”.

Jika kita analisis dari 10 ruang lingkup fasilitas kesehatan yang sudah ditetapkan dalam Peraturan Pemerintah No 47 Tahun 2016 diatas, maka dari 10 fasilitas pelayanan kesehatan sebagaimana dimaksud, kesemuanya berpotensi dapat menghasilkan limbah medis yang berbahaya, dan akan mengancam terhadap kualitas lingkungan hidup. Sehingga sudah sepatutnya dari seluruh fasilitas kesehatan tersebut perlu diatur tentang teknis pengelolaan limbah medisnya, namun sebagaimana dijelaskan diatas pengaturan mengenai pengelolaan limbah medis di fasilitas kesehatan yang diatur di dalam Peraturan menteri lingkungan hidup dan kehutanan nomor P.56/melhk-setjen/2015 tentang tata cara dan persyaratan teknis pengelolaan limbah bahan berbahaya beracun dari fasilitas pelayanan kesehatan, hanya mengatur mengenai teknis pengelolaan di 3 fasilitas kesehatan saja.

Sehingga dapat dilihat bahwa dengan tidak diaturnya fasilitas kesehatan pada Apotik, dan praktik bidan mandiri, menjadi ruang lingkup dalam pengelolaan limbah medis, maka hal tersebut tidak memberikan kepastian hukum terhadap teknis pengelolaan limbah yang dihasilkan oleh aktifitas nya dalam melakukan proses pelayanan kesehatan. Hal tersebut akan menjadi permasalahan, karena tidak diaturnya teknis pengelolaan limbah medis pada pelayanan kesehatan 


\begin{tabular}{llrr}
\hline \hline Volume: & 3 & E-ISSN: & 2655-1942 \\
Number: & 1 & Terbitan: & April 2020 \\
Page : & $15-28$ & & \\
\hline
\end{tabular}

terhadap, Apotik dan praktik bidan mandiri akan memunculkan penafsiran yang berbeda dalam mengelola limbah yang dihasilkannya masing-masing.

\section{Kesimpulan}

Limbah medis yang dihasilkan oleh fasilitas pelayanan kesehatan Apotik, dan praktik bidan mandiri dapat dikategorikan sebagai limbah B3, yang penanganannya harus bersifat khusus. Namun dalam pelaksanaan penanganan pengelolaan limbah medis yang dihasilkan oleh fasilitas pelayanan tersebut saat ini mengalami permasalahan, permasalahan tersebut dapat dilihat ketika tidak ada kepastian hukum dalam teknis pengelolaan limbah medis yang dihasilkan oleh Apotik, dan praktik bidan mandiri. Saat ini teknis pengelolaan limbah medis, hanya diatur pengelolaannya hanya pada fasilitas pelayanan kesehatan rumah sakit, puskesmas dan Klinik pelayanan kesehatan saja. Hal tersebut akan menjadi masalah karena teknis pengelolaan limbah medis pada pelayanan kesehatan Apotik dan praktik mandiri bidan, dalam pengelolaan limbah medisnya akan memunculkan penafsiran yang berbeda, dan berpotensi dapat mengancam terhadap kualitas kesehatan lingkungan.

Saran yang dapat penulis berikan adalah, agar sekiranya pemerintah dapat meregulasikan kembali mengenai teknis pengelolaan limbah medis yang dihasilkan oleh fasilitas pelayanan kesehatan yang sudah ditentukan di dalam peraturan pemerintah No 47 Tahun 2016, termasuk diantaranya adalah fasilitas kesehatan Apotik, dan praktik bidan mandiri.

Selanjutnya Saran lain yang dapat penulis berikan adalah bahwa pemerintah pusat perlu mendorong pemerintah daerah agar dapat berpartisipasi dalam mengatasi permasalahan ini dengan memberikan kewenangan kepada pemerintah daerah untuk menetapkan kebijakan tentang teknis pengelolaan limbah medis yang tidak diatur secara utuh ruang lingkupnya oleh Peraturan menteri lingkungan hidup dan kehutanan nomor P.56/melhk-setjen/2015 


\begin{tabular}{llrr}
\hline \hline Volume: & 3 & E-ISSN: & 2655-1942 \\
Number: & 1 & Terbitan: & April 2020 \\
Page : & $15-28$ & & \\
\hline
\end{tabular}

\section{DAFTAR PUSTAKA}

\section{Buku \& Jurnal}

Aymen Abd-ULSalam Awad, Enviromental Impact of Medical Waste Treatment And Management By Buring Inside Health Facilities, International Journal of Civil Engineering and Technology, Volume 9, Issue 5, May 2018

Benuf, Kornelius, and Muhamad Azhar, 'Metodologi Penelitian Hukum Sebagai Instrumen Mengurai Permasalahan Hukum Kontemporer', Gema Keadilan, 7.1 (2020), 20-33.

Busro, Achmad, 'Aspek Hukum Persetujuan Tindakan Medis (Inform Consent) Dalam Pelayanan Kesehatan', Law \& Justice Journal, 2018 <https://doi.org/10.14710/ldjr.v1i1.3570>.

Bunga Agustina, Kewenangan Pemerintah dalam Perlindungan Hukum Pelayanan Kesehatan Tradisional Ditinjau Dari Undang-Undang Republik Indonesia No 36 Tahun 2009 Tentang Kesehatan, Jurnal Wawasan Hukum, Vol. 32, No. 1, Februari 2015

Dewi Mustika, Analisis Pengelolaan Sampah Medis Pelayanan Kesehatan Praktik Bidan Swasta di Kota Banjar Baru, Jurnal Enviro Scienteae Volume 10 No 3 November 2014

Firman Freaddy Busroh, Konseptualisasi Omnibuslaw dalam Menyelesaikan Regulasi Pertanahan, ARENA HUKUM Volume 10, Nomor 2, Agustus 2017 Hanna Niken J Sihotang et al., Pertanggungjawaban Rumah Sakit Terkait dengan Tindak Pidana Lingkungan Hidup Yang Dilakukan Pegawai Rumah Sakit, USU Law Journal, Vol.3.No.1 April 2015

Kementerian Lingkungan Hidup dan Kehutanan, 2018, Peta Jalan (Roadmap)Pengelolaan Limbah B3 dari Fasilitas Pelayanan Kesehatan (Fasyankes) Direktorat Penilaian Kinerja Pengelolaan Limbah B3 dan Limbah Non B3 : Jakarta

Kornelius Benuf, Muhamad Azhar, Metodologi Penelitian Hukum sebagai Instrumen Mengurai Permasalahan Hukum Kontemporer, Gema Keadilan, Vol. 7, No. 1, 2020. 


\begin{tabular}{llrr}
\hline \hline Volume: & 3 & E-ISSN: & 2655-1942 \\
Number: & 1 & Terbitan: & April 2020 \\
Page : & $15-28$ & & \\
\hline
\end{tabular}

Mirawati et al. Analisis Sistim Pengelolaan Limbah Medis Padat Di Puskesmas Pangi Parigi Kabupaten Parigi Moutong, Jurnal Kolaboratif Sains Vol 1 No 1 tahun 2019

Mugeni Sugiharto, Oktarina, Environmental Health Program Implementation at Public Health Center (PHC) in Tuban District) - East Java Proviace (Analysis Data of National Health Facilities Research 2011), Buletin Penelitian Sistem Kesehatan - Vol. 17 No. 1 Januari 2014

Nopyandri, Hak atas Lingkungan Hidup dan Kaitannya dengan Peran Serta dalam Pengelolaan Lingkungan Hidup dalam Perspektif Otonomi Daerah, Jurnal Inovatif, Volume VII Nomor III September 2014

Robert Ohene Adu et al. Medical Waste-Sorting and Management Practices in Five Hospitals in Ghana, Journal of Environmental and Public Health Volume 4 March 2020,

Rochmani, Perlindungan Hak Atas Lingkungan Hidup Yang baik Dan Sehat Di

Masa Globalisasi, Jurnal Masalah-Masalah Hukum Vol 44 No 1 Januari 2015

Rosmidah Hasibuan, Pengaturan Hak Atas Lingkungan Hidup Terhadap Kesehatan, Jurnal Ilmiah “Advokasi” Vol. 06. No. 02 September 2018 Soerjono Soekanto, 1982Pengantar Penelitian Hukum, UI Press, Jakarta Soerjono Soekanto, 2007,Pengantar Penelitian Hukum, UI Press, Jakarta

Sri Nurhayati Qodriyatun, Bentuk Lembaga Yang Ideal Dalam Pengelolaan Sampah Di Daerah (Sudi di Kota Malang dan Kabupaten Gianyar), Jurnal Aspirasi Vol. 6 No. 1, Juni 2015

Zainudi Ali, 2009, Metode Penelitian Hukum, Sinar Grafika:Jakarta

\section{PERATURAN PERUNDANG-UNDANGAN}

Undang-Undang Dasar NRI Tahun 1945

Undang-Undang No 36 tahun 2009 Tentang Kesehatan

Undang-Undang No 18 Tahun 2008 Tentang pengelolaan sampah

Peraturan Pemerintah No 101 Tahun 2014 Tentang Pengelolaan limbah B3

PP No 47 Tahun 2016 


\section{Law, Development \& Justice Review}

\begin{tabular}{llrr}
\hline \hline Volume: & 3 & E-ISSN: & $2655-1942$ \\
Number: & 1 & Terbitan: & April 2020 \\
Page : & $15-28$ & & \\
\hline
\end{tabular}

Peraturan Menteri Lingkungan Hidup dan Kehutanan Nomor P.56/melhksetjen/2015 